\title{
Investigação sobre a existência de inovações disruptivas das grandes empresas multinacionais para o mercado brasileiro de baixa renda
}

\author{
Silvia Novaes Zilbera*, Francisco Lourenço da Silva ${ }^{\mathrm{b}}$ \\ a*silviazilber@gmail.com, UNINOVE, Brasil \\ bfrancisco.lourenco@aes.com, UNINOVE, Brasil
}

\begin{abstract}
Resumo
0 objetivo deste estudo foi identificar se grandes empresas multinacionais no mercado brasileiro, antes focadas prioritariamente nas classes de maior poder aquisitivo, promoveram algum tipo de inovação, particularmente inovações disruptivas, a fim de atender ao emergente mercado de baixa renda, impactando a gestão da produção e/ou cadeia de suprimentos dessas multinacionais. Para isso foi utilizado o método de estudo de casos múltiplos, estudando-se as empresas Nestlé, Unilever e Johnson \& Johnson. Os resultados mostraram que as multinacionais que atuam no mercado brasileiro estudadas não promoveram inovações disruptivas para atuar na base da pirâmide, pois consideraram que a faixa de classes D e E não é atrativa o suficiente para investirem no desenvolvimento de produtos para essa faixa, atendendo preferencialmente a classe $C$ através de pequenas modificações em produtos e distribuição. Dessa forma, não foram encontradas evidências de inovações disruptivas, mas inovações sustentadoras e incrementais ligadas à adequação de produtos existentes.
\end{abstract}

Palavras-chave

Inovação. Inovação disruptiva. Empresa multinacional. Base da pirâmide. Estratégia de crescimento.

\section{Introdução}

Há cerca de menos de dez anos a maior parte dos bens de consumo desenvolvidos e oferecidos por grandes empresas multinacionais eram direcionados aos segmentos sociais mais abastados. lsso está mudando e as principais empresas multinacionais já estão desenvolvendo iniciativas para o chamado mercado da base da pirâmide como forma de aumentar sua lucratividade, pois segundo Chan Kim e Mauborgne (2004), os altos níveis de competição nesses mercados desenvolvidos têm levado à redução das margens de lucro das grandes empresas devido à saturação natural do mercado.

Com o crescimento do mercado global ocorrido nos últimos anos, as grandes empresas passaram a focar os países emergentes como oportunidade de crescimento. Uma das principais características dos mercados emergentes é justamente a grande quantidade de pessoas que se situam nas camadas mais pobres da população, o que torna a criação de bens de consumo para esse mercado um desafio para as grandes empresas (LONDON; HART, 2004).

Prahalad e Hart (2002) e Prahalad e Hammond (2002) entendem como necessário que as grandes empresas devam focar a população pobre como consumidores a serem inseridos no mercado, devendo desenvolver produtos e serviços para essa população mais pobre, com preços e condições de pagamento adequados a este público e, na medida do possível, empregando-os na produção e distribuição desses bens. Desse modo, as empresas gerariam crescimento econômico nos mercados emergentes, trabalho para a população mais pobre e consequente mobilidade social.

Segundo Bower e Christensen (1995), Christensen (1997) e Hart e Christensen (2002), as grandes empresas estão habituadas a desenvolver inovações em caráter progressivo de aperfeiçoamento e melhoria contínua 
de seus produtos e serviços, as chamadas inovações sustentadoras. As grandes empresas preferem esse tipo de inovação, pois não implicam em grandes riscos, além de estarem focadas em clientes já conhecidos.

Porém, segundo Hart e Christensen (2002), para que as empresas consigam atingir o mercado de baixa renda é necessário um novo tipo de inovação denominada inovação disruptiva. Essa forma de inovação é voltada para o desenvolvimento de produtos/serviços destinados a clientes de segmentos de menor poder aquisitivo dispostos a consumir produtos menos sofisticados (com menor custo), porém com as funcionalidades adequadas a seu segmento. Segundo Utterback (1994), uma das razões da letargia de grandes competidores bem estabelecidos face à adoção potencial de inovação disruptiva deve-se ao fato de que essa inovação coloca as empresas frente a uma série de restrições relacionadas a mudanças em processos e produtos: mudanças em um elemento (produto) requerem mudanças no sistema global de materiais, equipamentos, métodos e fornecedores. lsso pode deixar a mudança gerada pela inovação disruptiva muito mais custosa para as firmas estabelecidas (multinacionais voltadas para as classes sociais de maior poder aquisitivo) do que para as novas entrantes.

Nosso interesse em focar a estratégia de inovação de grandes empresas multinacionais para classes sociais de menor poder aquisitivo no Brasil (base da pirâmide) deve-se a haver uma lacuna no estudo deste tema por pesquisadores acadêmicos, sendo que, por outro lado, a mídia vem explorando bastante o tema, a partir de meados dos anos 2000, dada a ascensão econômica da população de baixa renda: a impressão que se tem ao ler revistas e jornais é que todas as grandes empresas no Brasil perceberam o fenômeno de aumento do poder aquisitivo da população de menor renda devido a fatores econômicos e políticos desse período e elaboraram estratégias inovadoras para esse segmento. Segundo Neri (2010), em sua análise de dados do PNAD - Pesquisa Nacional por Amostra de Domicílios, do IBGE, no Brasil, cerca de 29 milhões de pessoas ingressaram na chamada nova classe média (classe C) entre 2003 e 2009. Segundo Quadros (2010), a partir da análise dos mesmos dados do PNAD, no período de 2004 a 2008, no Brasil "houve uma conjunção de fatores positivos que promoveu importantes melhorias sociais”. Esses dados mostram que existe um novo público, o de baixa renda em ascensão, atraente o suficiente para grandes empresas interessadas em ampliar sua participação no mercado.

Nesse contexto é que surgiu a ideia do presente estudo: verificar se, realmente, algumas grandes empresas multinacionais empreenderam esforços para conquistar esse segmento, alterando estratégias para esse fim, implicando no desenvolvimento de inovações.
Nesse sentido, o conceito inovação disruptiva parece bastante pertinente para o estudo do tema, dado que envolve o desenvolvimeno de produtos menos sofisticados que os voltados para as classes de maior poder aquisitivo, mas com funcionalidades que atendam ao segmento de menor renda, uma vez que a literatura esclarece que, entre as grandes corporações, algumas estão buscando conquistar este novo mercado, como forma de diversificação e para aumentar a lucratividade, porém muitas vezes sem conseguir. Um dos fatores que podem levar ao insucesso é a incapacidade de promover inovações disruptivas das grandes empresas, seja nos produtos, seja nos serviços, sejam as necessárias nos processos para o atendimento desse novo mercado (CHRISTENSEN, 1997), dado os custos de tais mudanças. Dessa forma, fica a questão: será que algumas empresas multinacionais que tentaram atender ao ascendente mercado de baixa renda no Brasil na década de 2000 empreenderam algum tipo de inovação disruptiva em seus produtos para adequá-los a essa camada social de menor renda - cujo aumento de poder aquisitivo associa-se ao especial momento político e econômico do país?

A maior parte da literatura a respeito de inovação disruptiva para atender ao mercado da base da pirâmide está focada nas experiências que ocorreram principalmente na índia. Por entendermos que os mercados emergentes são distintos e apresentam características próprias em cada país, estabelecemos os seguintes objetivos de pesquisa: entender como algumas das grandes empresas multinacionais que atuam no mercado brasileiro focadas prioritariamente na produção de bens de consumo para as classes socias de maior renda identificaram oportunidades no mercado de baixa renda, assim como entender quais estratégias de crescimento foram utilizadas por essas empresas para esse mercado e verificar se inovações disruptivas foram adotadas para atender esse segmento.

\section{Antecedentes teóricos}

Os antecedentes teóricos nesta seção subdividem-se em dois tópicos, a saber: renda e estratégia de mercado e inovação, que procuram embasar teoricamente a pesquisa realizada, com a apresentação de conceitos relevantes utilizados ao longo da pesquisa.

\subsection{Renda e estratégia de mercado}

Prahalad e Hart (2002) abordam a necessidade de as grandes empresas dirigirem suas operações para o que esses autores popularizaram como BOP 
(bottom of pyramid), ou seja, o estrato mais pobre da população. Eles quantificaram o tamanho deste potencial mercado em 4 bilhões de pessoas com base em fontes do World Development Reports (Nações Unidas). Entretanto existem vários níveis de pobreza na base da pirâmide, sendo o mais crítico o das pessoas que se encontram abaixo da linha da pobreza, definidas pelo Banco Internacional para a Reconstrução e o Desenvolvimento (BIRD) como pessoas com renda per capita inferior a US\$1.25/dia, que são os 1,4 bilhão de miseráveis no mundo. Portanto, a chamada base da pirâmide proposta por Prahalad e Hart (2002) é composta pela população pobre, sendo que 35\% dela é composta por pessoas abaixo da linha da pobreza, a renda per capita das demais varia de US\$2.00 a US\$ 4.00/dia.

Cabe ressaltar que a pobreza de um país ou região pode ser relativa, e o seu conceito pode variar, sendo que há muito tempo tenta-se aferir o grau de pobreza de modo a equiparar esses conceitos. Segundo Burkhauser, Feng e Jenkins (2007), foram criados diversos índices estatísticos para analisar essas questões de distribuição de renda na economia, tais como P90/P10, coeficiente de Gini, T de Theil, entre outros indicadores como, por exemplo, o Índice de Desenvolvimento Humano (IDH).

Neste estudo utilizam-se como referência para a classificação do mercado consumidor os valores adotados pela Associação Brasileira de Empresas de Pesquisa (ABEP), que leva em conta o Critério de Classificação Econômica Brasil (CCEB). Esse critério segmenta a população segundo seu poder de compra, avaliando as classes econômicas por critério de pontuação atribuído de acordo com a posse de determinados bens de consumo e o grau de instrução do chefe de família.

Segundo London e Hart (2004), o mercado de baixa renda representa uma enorme oportunidade para as organizações multinacionais considerando-se seu volume. Entretanto, para Anderson e Billou (2007) e SadreGhazi e Duysters (2008), apesar das oportunidades existentes, as empresas multinacionais apresentam um longo histórico de fracasso ao tentar entrar em mercados de baixa renda, principalmente por tentarem reproduzir estratégias originalmente concebidas para mercados de alto padrão.

Com a grande competição de mercado, muitas organizações buscam estratégias de crescimento como forma de obter aumento de lucratividade, sendo que alguns autores - London e Hart (2004), Prahalad (2005), Seelos e Mair (2007), SadreGhazi e Duysters (2008) - apontam que focar também o mercado da base da pirâmide atende à necessidade de diversificação da empresa. Para Ansoff (1958), a estratégia de crescimento baseada na matriz produto-mercado constitui oportunidade de ampliação das vendas através da estratégia de expansão da empresa ou da busca de novas oportunidades, tanto em novos produtos como em novos mercados, bem como através da diversificação pura, definida como estratégia empresarial de oferecer novos produtos ou serviços destinados a diferentes mercados.

Segundo Seelos e Mair (2007), a dificuldade de atender ao mercado da base da pirâmide aumenta à medida que esse mercado possui grande quantidade de pessoas abaixo da linha da pobreza. De acordo com Anderson e Billou (2007), além das dificuldades internas, as grandes empresas enfrentam fatores como falta de conhecimento do novo mercado, corrupção elevada em países pobres, falta de infraestrutura básica e outros para atender ao mercado da base da pirâmide.

Anderson e Markides (2007) e Anderson e Billou (2007) estabelecem como fatores de sucesso para as empresas multinacionais que buscam o mercado de baixa renda em países emergentes, a adoção de inovações estratégicas baseadas no que esses autores chamam de "4 As" (affordability; acceptability; availability; awareness), ou seja, deve-se prever alternativas para que consumidores de baixa renda também possam adquirir bens e serviços, bem como deve-se satisfazer as necessidades específicas de tais clientes, com novas funções, e também garantir a disponibilidade dos produtos e serviços à comunidade.

\subsection{Inovação}

Schumpeter (1982) foi o primeiro a dar à inovação um lugar de destaque na teoria do desenvolvimento econômico, pois entende que a inovação permite à empresa superar a concorrência perfeita, estabelecendo uma situação de monopólio temporário ao criar um novo mercado para seus produtos. Segundo o Manual de Oslo da OCDE - Organização para Cooperação e Desenvolvimento Econômico (2004), as inovações tecnológicas compreendem tanto as implantações de produtos e processos tecnologicamente novos como substanciais melhorias tecnológicas em produtos e processos existentes. De modo geral, as inovações são caracterizadas sob duas dimensões: o que é mudado e a extensão percebida da mudança. De acordo com Tidd, Bessant e Pavitt (2005), a primeira dimensão está relacionada ao objeto do processo de inovação, que pode ser um produto, serviço ou processo. Quanto à segunda dimensão da inovação, segundo Carayannis, Gonzalez e Wetter (2003), a mesma está associada ao grau de novidade envolvido, que se estende desde pequenas melhorias incrementais até mudanças radicais que transformam a maneira pela quais os produtos são concebidos ou utilizados, sendo 
essa a inovação incremental, que explora o potencial das estruturas atuais da empresa.

Para Christensen (2001), os modelos estratégicos são temporais e estão vinculados a condições que podem mudar ao longo do tempo. De acordo com Christensen (1997), as inovações sustentadoras são as obtidas por melhorias incrementais promovidas nos produtos e serviços da empresa visando atender usuários consumidores de novidades, que são mais exigentes e sofisticados. Segundo Christensen, Johnson e Rigby (2002), as empresas líderes de mercado quase sempre ganham a competição usando o enfoque da inovação sustentadora, pois dispõem de recursos e competências suficientes para sair com vantagens e ser vencedoras, o que gera uma acomodação por parte dos gerentes dessas empresas, que relutam em buscar outro tipo de inovação. Para Christensen (1997), Christensen, Craig e Hart (2001), Burlamaqui e Proença (2003), as grandes empresas vivem o dilema de buscar a competição com base nas inovações sustentadoras para evitar grandes riscos, atuando sempre em mercados de maior margem e com menor espaço de tempo.

Christensen (1997) identificou dois tipos de inovações voltadas para o segmento de baixa renda chamadas de disruptivas: 1) Disrupções de baixo mercado: no seu afã de oferecer um produto ou serviço sempre melhor, as empresas estabelecidas acabam desenvolvendo um produto com desempenho superior ao exigido pela média do mercado. Essa situação abre espaço para que um novo entrante ofereça um produto com desempenho bom mas inferior ao dos líderes de mercado, adotando uma nova abordagem que o torna mais barato ou mais conveniente ou fácil de usar. 2) Disrupção de novo mercado: nesse caso o produto apresenta baixo desempenho nos atributos "tradicionais", mas melhor desempenho em novos atributos, tipicamente simplicidade e conveniência.

Ainda segundo Christensen (1997), os conceitos de inovação disruptiva e sustentadora têm menos a ver com a tecnologia em si e mais em como essa tecnologia afeta o modelo de negócios da empresa que conduz essas inovações. Portanto, segundo ele, uma inovação de ruptura caracteriza-se pelo fato de exigir um novo modelo de negócios, pode-se achar difícil a adoção desse novo modelo por empresas estabelecidas que atendem ao segmento de maior poder aquisitivo, pois implicaria inicialmente em menores margens, menor crescimento e produtos que não são o que os seus principais clientes querem (por terem menor qualidade). Conforme Hart e Christensen (2002), é possível, por meio da inovação disruptiva, atingir o mercado de baixa renda, pois o mesmo é composto por dois tipos de clientes potenciais, ou seja, tanto o consumidor que necessita de preço baixo e está disposto a abrir mão de funcionalidades do produto, bem como novos consumidores que estão entrando no mercado formal.

Segundo Christensen, Johnson e Rigby (2002), os gerentes das empresas precisam reconhecer as oportunidades de inovação e para isso é necessário saber identificar de fato as duas categorias de inovação: sustentadoras e disruptivas. Christensen e Raynor (2003) entendem por inovação disruptiva de novo mercado aquela que irá atender até então não consumidores de um determinado produto ou serviço e inovação de baixo mercado, aquela que atrai consumidores já saciados ou mais do que satisfeitos na camada inferior do mercado.

De acordo com Anderson e Markides (2007), preços e margens menores para a inovação oferecida a determinados grupos de clientes não significa que os fornecedores dessas inovações disruptivas menos sofisticadas faturem menos, mas sim que faturam de maneira diferente: com custos gerais indiretos mais baixos, processo de vendas distinto e maior utilização de seus recursos para compensar os preços unitários mais baixos.

\section{Metodologia}

Este trabalho utilizou pesquisa exploratória por meio de estudo de casos múltiplos. Segundo Eisenhardt (1989) e Yin (2001), o estudo de caso é uma estratégia de pesquisa focada no entendimento da dinâmica atual dentro de um cenário único, podendo envolver um único caso ou múltiplos casos e, além disso, níveis diferenciados de análise. No desenvolvimento de estudo de caso com abordagem qualitativa existe o risco da superficialidade de o estudo limitar-se exclusivamente a uma análise descritiva de processos, no entanto Eisenhardt (1989) sugere que se realize coleta de dados utilizando múltiplos métodos para permitir a triangulação das informações, recomendação seguida neste estudo.

Alguns autores, Eisenhardt (1989) e Yin (2001) dentre eles, colocam como grande vantagem da utilização de estudos de caso o fato de ele permitir ao pesquisador concentrar-se em um aspecto ou situação específica e identificar, ou tentar identificar, os diversos processos que interagem no contexto estudado. Esses autores argumentam que enquanto os questionários e outros métodos estruturados conseguem respostas apenas aos aspectos especificamente questionados, os estudos de caso são mais receptivos a informações não previstas pelo pesquisador, tendo como ponto forte sua capacidade de explorar processos sociais à medida que esses ocorrem nas organizações. Julgou-se adequado esse método no momento da realização da 
presente pesquisa, dada a ausência de outros estudos sobre o tema que pudessem preencher as lacunas de conhecimento sobre se as grandes multinacionais adotaram inovações disruptivas para atender ao mercado da base da pirâmide.

Neste trabalho estabeleceu-se como unidade de pesquisa as empresas multinacionais de grande porte que normalmente atuam no mercado brasileiro com foco prioritariamente nas classes econômicas de maior poder aquisitivo e que nos últimos anos passaram a fazer investidas no mercado de baixa renda. A princípio, para eleger as empresas que se enquadravam nesse universo, buscou-se por meio de pesquisas de reportagens na internet e em mídia eletrônica sobre negócios que citassem empresas com esse perfil e que estavam atuando no chamado mercado da base da pirâmide. Estabeleceu-se um corte transversal, selecionando apenas reportagens entre 2003 e 2008. Verificou-se assim que o universo da pesquisa era inferior a uma dezena de empresas (as principais: Nestlé, Unilever, Johnson \& Johnson, Oi, Casas Bahia, Nokia, Procter \& Gamble, Sadia, Telefônica e outras citadas com frequência menor) e que as mais citadas estão relacionadas à produção de bens de consumo.

Dessa forma, a ideia inicial de realização de um survey tornou-se impraticável dada a pequena quantidade de empresas que se adequavam aos objetivos desta pesquisa citadas na mídia.

Para a pesquisa, as três empresas estudadas - Nestlé, Unilever e Johnson \& Johnson - foram selecionadas, primeiro, pelo critério citado, ou seja: foram as que mais tiveram citações nas mídias pesquisadas como empresas que desenvolvem ações voltadas para a baixa renda. Além dessa qualidade comum às três, outros critérios foram: além de a Nestlé ser uma das maiores empresas alimentícias do mercado brasileiro e de seu produto ser considerado essencial pela classe de renda mais baixa, ela foi selecionada porque, por seus esforços na adequação das operações para atender a esse mercado de renda mais baixa, é a que mais aparece na mídia relacionada ao tema.

A Unilever foi selecionada pelo seu longo histórico no desenvolvimento de soluções para o mercado de baixa renda no setor de alimentação, limpeza e higiene, segmento no qual a maturidade acumulada permite que, hoje, a empresa dissemine esse conhecimento entre suas unidades de negócio. E, por fim, a Johnson \& Johnson, também selecionada por atuar no setor de produtos de higiene pessoal, despertou interesse pelo fato de ter entrado tardiamente no processo de focar o mercado de baixa renda, em razão do que perdeu participação no mercado, a qual busca novamente aumentar.
Para a coleta dos dados primários, optou-se pela entrevista semiestruturada a fim de garantir uma estrutura mínima que permitisse comparar entrevistas distintas. Após contatos com diversas pessoas que atuam especificamente no mercado de baixa renda de cada empresa, foi definido como público-alvo das entrevistas os gerentes que participaram diretamente do processo de atendimento ao mercado de baixa renda, por serem os elementos mais significativos, devido à visão mais ampla que tinham do processo e por seu acesso a uma maior quantidade de informações sobre o processo. Os gerentes entrevistados (num total de seis) eram de setores de inteligência de negócio, desenvolvimento de produtos ou desenvolvimento de novos negócios, sendo que posteriormente foram estabelecidos mais contatos complementares (telefônicos e troca de e-mails).

Com o intuito de garantir a validade dos dados coletados, adotou-se a estratégia de triangulação, sendo que Flick (2004) relaciona quatro tipos de triangulação: dos dados; dos pesquisadores; da teoria; e da metodologia. Neste estudo considerou-se o uso de triangulação dos dados. Além dos dados primários, foram objeto de triangulação e análise diversas fontes de evidências obtidas em dados secundários, tais como: reportagens sobre a atuação das empresas selecionadas; materiais obtidos nos sites das empresas, ou fornecidos diretamente pelas mesmas; fatos baseados em documentários e material de propaganda, além de teses, dissertações e artigos acadêmicos, fornecendo um vasto material de consulta e fonte de informação.

Quanto à análise dos dados secundários e primários, utilizou-se a técnica de análise de conteúdo, que, conforme definição de Bardin (2008), é realizada em três momentos: na pré-análise, na exploração do material e no tratamento dos resultados por meio de inferência e interpretação.

Na pré-análise é organizado o material selecionado, que foi agrupado em um único documento, denominado unidade hermenêutica, sendo que esta seleção do material obedeceu em princípio aos critérios de exaustividade, representatividade, homogeneidade, pertinência e exclusividade. Todos os dados, com cerca de 200 páginas, foram inseridos em um único documento no software Atlas Tl, utilizado como ferramenta-suporte na gestão das documentações, facilitando o processo de análise, armazenagem e controle, além de permitir a codificação de trechos do texto, inclusão de notas, comentários, citações, esquemas gráficos de inter-relacionamento entre codificações e agrupamento de codificações em famílias.

De acordo com Bardin (2008), na exploração do material ocorre a fase mais longa, na qual é feita 
a codificação, processo em que os dados brutos passam para a forma organizada, agregados em unidades, permitindo uma descrição das características pertinentes do conteúdo. A codificação compreende três fases distintas: escolha de unidades de registro; seleção de regras de contagem; e escolha de categorias.

A unidade de registro é a unidade de significação a codificar, podendo ser o tema, palavra ou frase (palavras-chave; palavras-tema; palavras plenas; categorias de palavras: substantivos, adjetivos, verbos etc.). 0 texto contido na unidade hermenêutica é recortado em função da unidade de registro - nessa pesquisa as unidades de registro foram estabelecidas conforme na Tabela 1:

Após a segmentação do texto estruturada pelas unidades de registro, o software Atlas $\mathrm{Tl}$ permite filtrar os trechos apreendidos por unidade de registro, ou seja, pode-se constatar a frequência com que aparecem no texto. Segundo Bardin (2008), essa é fase de seleção das regras de contagem, na qual se verifica a presença de elementos que podem ser significativos, assim como também a ausência, que pode significar bloqueios ou traduzir vontade oculta.
Ainda segundo Bardin (2008), categoria é uma forma geral de conceito ou de pensamento que reúne um grupo de unidades de registro em razão de características comuns. A Tabela 2 apresenta a relação de categorias estabelecidas neste trabalho, algumas como resultado de agrupamentos textuais e outras do agrupamento de unidades de registro.

Para a interpretação dos dados na análise de conteúdo, é preciso voltar atentamente aos marcos teóricos pertinentes à investigação, pois eles dão o embasamento e as perspectivas significativas para o estudo. A relação entre os dados obtidos e a fundamentação teórica é que darão sentido à interpretação.

\section{Resultados e análises}

A seguir apresentamos as principais características e dados obtidos em cada empresa estudada e a análise com base na revisão da literatura.

Antes de iniciar a apresentação dos resultados, é interessante apresentar os dados demográficos

Tabela 1. Relação de unidades de registro. Fonte: elaborado pelos autores.

\begin{tabular}{|c|c|}
\hline Unidade de registro & Contexto \\
\hline Penetração de mercado & $\begin{array}{l}\text { ldentificação de ações que demonstrem a busca da ampliação das vendas em mercados existentes e com } \\
\text { produtos existentes, conforme Ansoff (1958). }\end{array}$ \\
\hline Desenvolvimento de produto & $\begin{array}{l}\text { ldentificação de ações que demonstrem a busca da ampliação das vendas em mercados existentes, porém } \\
\text { com produtos novos, conforme Ansoff (1958). }\end{array}$ \\
\hline Desenvolvimento de mercado & $\begin{array}{l}\text { ldentificação de ações que demonstrem a busca da ampliação das vendas em mercados novos, porém com } \\
\text { produtos existentes, conforme Ansoff (1958). }\end{array}$ \\
\hline Diversificação & $\begin{array}{l}\text { ldentificação de ações que demonstrem a busca da ampliação das vendas em mercados novos e com } \\
\text { produtos novos, conforme Ansoff (1958). }\end{array}$ \\
\hline Inovação sustentadora & $\begin{array}{l}\text { Melhorias incrementais promovidas nos produtos e serviços da empresa, visando atender a usuários } \\
\text { consumidores de novidades, que são mais exigentes e sofisticados, conforme Christensen (1997). }\end{array}$ \\
\hline Inovação incremental & $\begin{array}{l}\text { Pequenas inovações em produtos e serviços com pequenas alterações na composição dos mesmos, sem } \\
\text { necessariamente atender a usuários diferenciados ou transformar processos, observar Schumpeter (1982). }\end{array}$ \\
\hline lnovação radical & $\begin{array}{l}\text { Grandes inovações em produtos, serviços e processos, com significativas alterações na composição dos } \\
\text { mesmos. Mudanças radicais que transformam a maneira pela quais os produtos são concebidos ou } \\
\text { utilizados, observar Schumpeter (1982). }\end{array}$ \\
\hline Inovação disruptiva & $\begin{array}{l}\text { lnovação que visa romper e redefinir modelos de negócios vigentes, combinando ou não tecnologias do } \\
\text { momento, sem a preocupação de excelência tecnológica. Conforme Christensen (1997), disrupção de } \\
\text { baixo mercado (novo entrante oferece um produto com desempenho bom, mas inferior ao dos líderes de } \\
\text { mercado, adotando uma nova abordagem que o torna mais barato ou mais conveniente ou fácil de usar) } \\
\text { e disrupção de novo mercado (produto com baixo desempenho nos atributos "tradicionais" mas melhor } \\
\text { desempenho em novos atributos, tipicamente simplicidade e conveniência). }\end{array}$ \\
\hline
\end{tabular}

Tabela 2. Relação de categorias. Fonte: elaborado pelos autores.

\begin{tabular}{cl}
\hline \multicolumn{1}{c}{ Categoria } & \multicolumn{1}{c}{ Objetivo específico associado } \\
\hline $\begin{array}{c}\text { ldentificação de } \\
\text { oportunidades }\end{array}$ & $\begin{array}{l}\text { Agrupamento de elementos textuais e unidades de registro que estão associados ao objetivo específico de } \\
\text { entender como as grandes empresas estabelecidas no mercado brasileiro identificam oportunidades no mercado } \\
\text { de baixa renda. }\end{array}$ \\
\hline \multirow{2}{*}{ Estratégia de crescimento } & $\begin{array}{l}\text { Agrupamento de elementos textuais e unidades de registro que estão associados ao objetivo específico de } \\
\text { entender quais estratégias de crescimento são utilizadas por grandes empresas estabelecidas no mercado } \\
\text { brasileiro para atender também ao mercado de baixa renda. }\end{array}$ \\
\hline Agrupamento de elementos textuais e unidades de registro que estão associados ao objetivo específico de \\
analisar as possíveis inovações em produtos, serviços, ou processos implantados pelas grandes empresas \\
estabelecidas no mercado brasileiro para poder atender também ao mercado de baixa renda.
\end{tabular}


brasileiros, que apresentam certas peculiaridades com relação aos demais países emergentes, afetando as análises realizadas.

As multinacionais estudadas nesta pesquisa abordam o mercado por regiões e não países, sendo que, no caso do Brasil, o mercado é visto em âmbito de América Latina. Verifica-se que os principais países dessa região que concentram unidades fabris e centros de pesquisa das empresas analisadas são Argentina, Brasil, Chile e México, países que, diferentemente da Índia, não concentram tantas pessoas na camada mais baixa da base da pirâmide (classes D e E) - Prahalad e Hart (2002) e Prahalad e Hammond (2002). Sendo assim, o principal ganho de escala na produção de bens para a chamada base da pirâmide (classes D e E) não se justifica em termos de investimento. Devido à escala, no caso especifico do mercado brasileiro, que é foco desta pesquisa, o interesse das multinacionais volta-se para a chamada classe C.

Conforme Figura 1, abaixo, no caso do mercado brasileiro observa-se graficamente que temos um losango e não uma pirâmide social, no qual o vértice inferior representa a classe E composta por famílias com cerca de quatro pessoas. Isso resulta num rendimento médio individual de 1,25 dólar/dia, ou seja, encontram-se abaixo da linha da pobreza e, portanto, não possuem condições financeiras e não são foco das empresas. Do mesmo modo, a chamada classe $\mathrm{D}$ também tem um poder aquisitivo muito baixo, da ordem de 2,5 dólares/dia per capita. 0 principal foco das grandes empresas instaladas no Brasil é justamente a classe $\mathrm{C}$, com rendimento médio por pessoa de 5 dólares/dia, que representam mais de $42 \%$ da população. Considerando-se a faixa de pessoas na iminência de passar da classe D para a C, estamos focando cerca de 50\% da população e uma movimentação de riqueza da ordem de 460 milhões de dólares/dia.

Segundo Neri (2010), analisando dados do PNAD/IBGE, “a renda média por brasileiro cresceu
$2,04 \%$ no ano da crise, apesar do repique do desemprego e da queda da taxa de ocupação". Ainda segundo Neri (2010), ocorreu uma redução da pobreza no período de 2003 a 2008: nesse período, 19,5 milhões de pessoas saíram da pobreza, o que ressalta a atratividade dessa nova massa de potenciais consumidores para as multinacionais instaladas no Brasil, como dito no início do presente artigo.

Segundo Neri (2010), numa atualização da Figura acima, a partir da análise dos dados do PNAD/1BGE, em 2009, os 94,9 milhões de brasileiros que se encontram na nova classe média (C) representam 50,5\% da população brasileira, concentrando 46,24\% do poder de compra dos brasileiros em 2009 sendo, portanto e ainda segundo esse autor, a classe dominante do ponto de vista econômico.

No Brasil, o mercado de baixa renda está diretamente associado à classe $\mathrm{C}$ e à parte da classe D que já participa do mercado formal de consumo. Feita essa análise, que irá impactar os resultados obtidos dada a configuração da baixa renda no Brasil ser diferente daquela estudada por Prahalad na Índia, seguem os resultados obtidos por empresa na presente pesquisa.

\subsection{Nestlé}

Os primeiros produtos da Nestlé surgiram no Brasil por meio da importação, mas há quase 90 anos a empresa passou a produzir também em território brasileiro, em sua primeira fábrica, instalada no interior de São Paulo. Para a Nestlé, o Brasil é, em volume de produção, o segundo maior mercado e o quinto maior faturamento. No Brasil, a empresa é líder no setor alimentício, contando com 15 filiais de vendas espalhadas por todo o território nacional, além de cinco centros de distribuição e quatro depósitos. A infraestrutura da Nestlé no Brasil também compreende 26 unidades fabris.

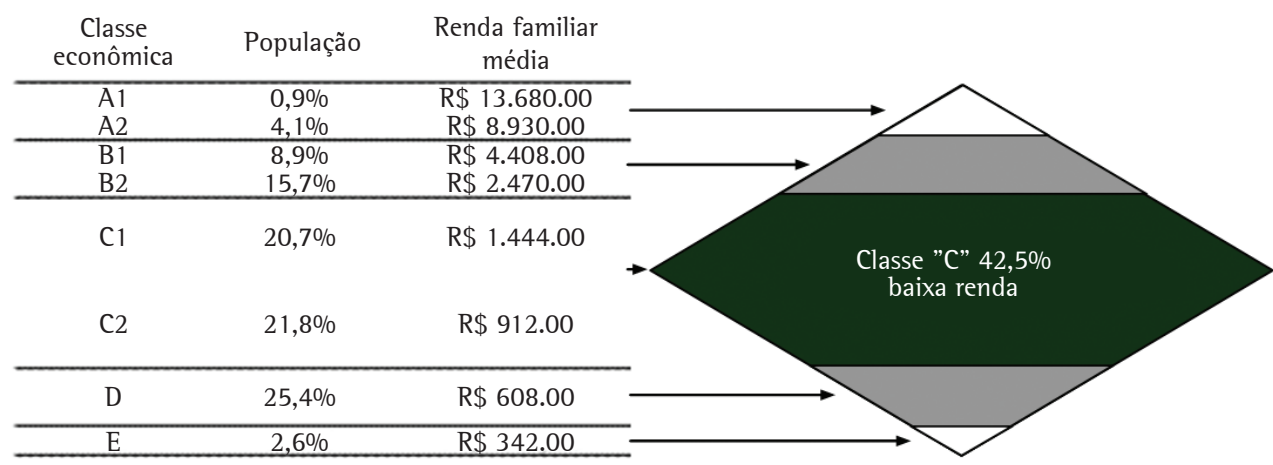

Figura 1. Representatividade da classe C. Fonte: elaborado pelos autores com base nos critérios da ABEP (CCEB). 
A seguir, apresentamos a Tabela 3 , com as codificações encontradas no levantamento, conforme estabelecido na metodologia desta pesquisa.

Não foram encontradas na Nestlé evidências da presença de unidades de registro de inovação disruptiva, desenvolvimento de mercado, e diversificação.

A análise da Nestlé apresentou várias evidências de identificação de oportunidades no segmento alimentício, relacionadas tanto a volume de mercado como ao fato de a empresa possuir muitos produtos considerados relevantes pelo mercado de baixa renda. Além das oportunidades, foi identificado o direcionamento de ações para a classe $C$ que já consome normalmente os produtos da Nestlé e esta, por sua vez, prefere centrar seus esforços de crescimento na chamada "penetração de mercado".

A seguir apresentamos a Figura 2, com as relações encontradas no levantamento conforme estabelecido na metodologia desta pesquisa.

Conforme Figura 2, a estratégia de crescimento adotada pela Nestlé está centrada na penetração de mercado, conforme Ansoff (1958), e para o sucesso da mesma, verifica-se grande frequência no uso de inovações incrementais e sustentadoras relacionadas à adequação de produtos, assim como inovações radicais relacionadas à adequação de canal de distribuição, como por exemplo a venda porta a porta. Foram encontradas menções quanto a produtos diferenciados pela qualidade, assim como considerados aspiracionais, mas quanto ao desenvolvimento de produtos inteiramente novos foram encontradas poucas evidências e essas estavam relacionadas mais à adequação de produtos existentes.

\subsection{Unilever}

A empresa, fundada na Inglaterra, no século XIX, começou com a criação de uma fábrica de sabão. Nessa época, o sabão era um produto genérico, vendido por peso, e a empresa inovou com a criação de uma embalagem com a marca do produto. Com o sucesso da marca, ela se expandiu e em 1929 uniu-se a um grupo holandês da área de alimentos. Dentro da sua estratégia de expansão, no mesmo ano a empresa chega ao Brasil, à cidade de São Paulo, cujo escritório importava da matriz, na Inglaterra, o sabão para lavar roupas delicadas. Entretanto, no mesmo ano, devido à quebra da bolsa de valores de Nova York, surgiram dificuldades para a importação, o que levou a empresa a investir na instalação de uma fábrica no Brasil.

Tabela 3. Codificações encontradas no caso Nestlé. Fonte: elaborado pelos autores.

\begin{tabular}{|c|c|c|}
\hline Categorias & Unidades de registro & Resultados encontrados \\
\hline $\begin{array}{l}\text { Identificação de } \\
\text { oportunidade }\end{array}$ & \multicolumn{2}{|c|}{$\begin{array}{l}\text { A Nestlé busca oportunidades no mercado brasileiro de baixa renda, pois existe um grande potencial, estimado } \\
\text { em mais de R\$ } 150 \text { bilhões/ano, na área de alimentação, neste mercado }\end{array}$} \\
\hline \multirow{2}{*}{ Estratégia de crescimento } & Penetração de mercado & Alteração no canal de distribuição \\
\hline & Desenvolvimento de produto & Alteração da composição do produto e/ou da embalagem \\
\hline \multirow{3}{*}{ lnovação } & lnovação sustentadora & Relacionada à alteração de tamanho das embalagens \\
\hline & Inovação incremental & $\begin{array}{l}\text { Relacionada a alterações da composição dos produtos e das } \\
\text { embalagens }\end{array}$ \\
\hline & Inovação radical & Relacionada à criação de novo canal de distribuição de produtos \\
\hline
\end{tabular}

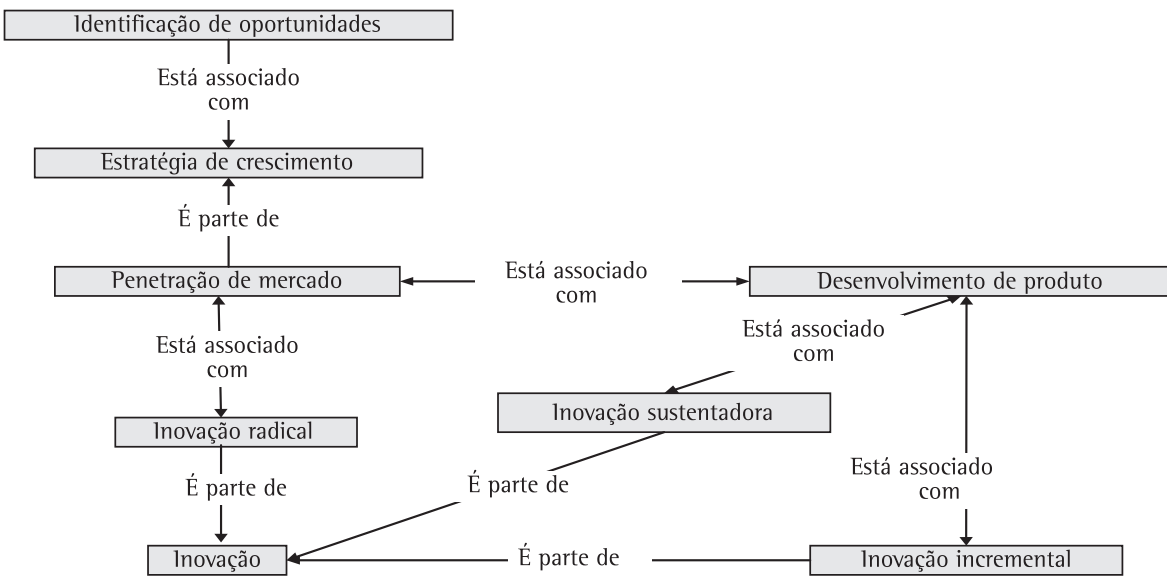

Figura 2. Relações encontradas no caso Nestlé. Fonte: elaborado pelos autores com base nos resultados obtidos com o Atlas Tl. 
Desde a sua origem, a Unilever sempre esteve envolvida em processos de inovação e passou por grandes modificações em sua estrutura ao longo do tempo devido a sucessivos processos de compra e fusão com outras empresas. Em 2000, realizou fusão internacional com uma empresa americana o que resultou em um salto na sua participação no mercado de alimentos, com portfólio renovado por marcas de grande penetração e tradição no Brasil. Acompanhando o conjunto de mudanças internas que se inicia após essa última aquisição, a Unilever adota seu nome internacional e reorganiza seu portfólio de marcas, saindo das mais de 1.600 ao redor do mundo para a faixa de 400 . Elas representam $93 \%$ de seus negócios, foram definidas como leading brands e estão sendo trabalhadas nesse sentido, ao lado de 250 outras que estão em processo de desaparecimento (ou venda). 0 grupo é um dos fornecedores líderes de produtos de consumo no mundo, sendo estruturado em três ramos de negócios globais: alimentos; higiene; e beleza. Atualmente, a Unilever conta no Brasil com 13 fábricas, quatro das quais são das maiores operações que a companhia desenvolve globalmente.
A seguir apresentamos a Tabela 4, com as codificações encontradas no levantamento conforme estabelecido na metodologia desta pesquisa.

Não foram encontradas na Unilever evidências da presença de unidades de registro de inovação radical, inovação disruptiva, desenvolvimento de mercado e diversificação.

A seguir, apresentamos a Figura 3 com as relações encontradas no levantamento conforme estabelecido na metodologia desta pesquisa.

A Unilever possui longo histórico de iniciativas de atuação no mercado de baixa renda e apresentou várias evidências de identificação de oportunidades nos diversos segmentos em que atua, relacionados principalmente ao fato de possuir muitos produtos considerados relevantes pelo mercado de baixa renda. Essas oportunidades também estavam relacionadas ao grande interesse pela classe $\mathrm{C}$, que promoveu a estratégia de crescimento baseada em penetração de mercado, conforme conceito estabelecido por Ansoff (1958).

Tabela 4. Codificações encontradas no caso Unilever. Fonte: elaborado pelos autores.

\begin{tabular}{|c|c|c|}
\hline Categorias & Unidades de registro & Resultados encontrados \\
\hline $\begin{array}{l}\text { Identificação de } \\
\text { oportunidade }\end{array}$ & $\begin{array}{l}\text { A Unilever já desenvolve estudos so } \\
\text { crescimento desse mercado, pois ap } \\
\text { pessoas das classes C, D e E, e no r }\end{array}$ & $\begin{array}{l}\text { nercado de baixa renda há mais de } 10 \text { anos - seu interesse é no } \\
\text { nadamente } 8 \% \text { de seus produtos alimentícios são consumidos por } \\
\text { de limpeza ela controla } 80 \% \text { do mercado de detergentes. }\end{array}$ \\
\hline \multirow[t]{2}{*}{ Estratégia de crescimento } & Penetração de mercado & $\begin{array}{l}\text { Ampliação de vendas devido a adequações e desenvolvimento de } \\
\text { produtos e redução de preço. Foco: Nordeste }\end{array}$ \\
\hline & Desenvolvimento de produto & Alteração da composição do produto e/ou da embalagem \\
\hline \multirow[b]{2}{*}{ lnovação } & Inovação sustentadora & Relacionada à alteração de tamanho das embalagens \\
\hline & Inovação incremental & $\begin{array}{l}\text { Relacionadas a alterações da composição dos produtos e das } \\
\text { embalagens }\end{array}$ \\
\hline
\end{tabular}

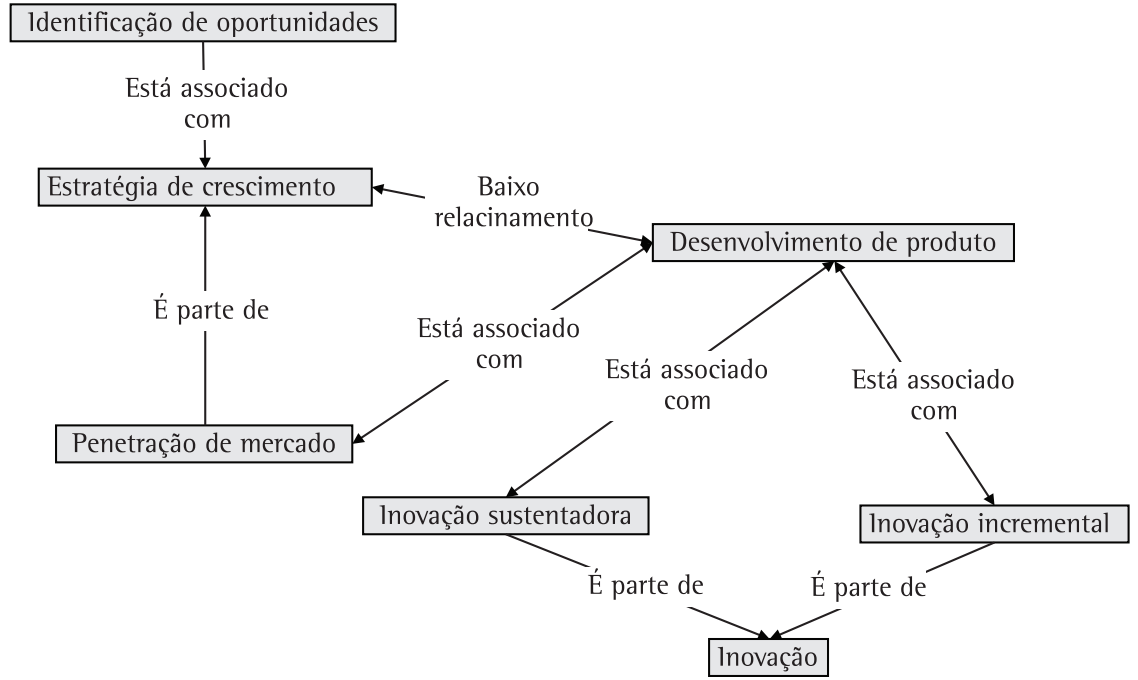

Figura 3. Relações encontradas no caso Unilever. Fonte: elaborado pelos autores com base nos resultados obtidos com o Atlas Tl. 
Foram encontradas evidências quanto a produtos considerados aspiracionais, mas quanto ao desenvolvimento de produtos inteiramente novos, de acordo com a Figura 3, foram encontradas poucas evidências e essas estavam relacionadas mais com a adequação de produtos existentes ou com o uso de sua larga competência no conhecimento dos produtos tradicionalmente desenvolvidos pela empresa. 0 único caso relevante de inovação que poderia ser chamada de disruptiva foi o desenvolvimento do sabão em pó Ala, vendido exclusivamente no Norte e Nordeste brasileiro, produto voltado para a população de baixa renda, oferecido a preço mais acessível e com atributos desenvolvidos visando as funcionalidades requeridas por aquele mercado. Ala foi lançado em 1996 e surgiu como resultado de uma profunda pesquisa realizada com as mulheres das classes $C$ e D do Norte e Nordeste, na qual elas apontaram os principais benefícios exigidos para uma marca de detergente em pó, levando ao desenvolvimento de um produto totalmente novo. Esse caso, porém, frente ao imenso portfólio de produtos da Unilever, não registra uma tendência da empresa, que prefere adaptar embalagens, mudar quantidade do produto, ou seja, realizar adequação de produtos, o que não denota uma estratégia de inovação disruptiva.

\subsection{Johson \& Johnson}

A empresa Johnson \& Johnson (J\&J) nasceu há mais de 120 anos numa pequena cidade nos Estados Unidos, a partir da ideia de criar a primeira fábrica no mundo a produzir uma compressa cirúrgica asséptica pronta para uso, o que reduziria a ameaça de infecção. Fabricando compressas e desenvolvendo novos processos de esterilização, a empresa iniciou sua expansão internacional na década de 20 , com a abertura de uma filial no Canadá. 0 primeiro passo na diversificação de seus produtos foi o lançamento da compressa patenteada, que promoveu o crescimento da empresa e sua organização em divisões e subsidiárias, hoje presentes em 51 países, nos cinco continentes, com produtos comercializados em mais de 175 países.

A Johnson \& Johnson do Brasil é uma das maiores afiliadas do grupo fora dos Estados Unidos.
Sua chegada ao país aconteceu na década de 30 , para suprir o mercado brasileiro com produtos de uso hospitalar e doméstico, como algodão, gaze, esparadrapo e compressas cirúrgicas, entre outros. No Brasil, ela conta com um dos quatro centros de pesquisa que mantém mundialmente, o único a realizar pesquisas sobre determinados produtos, como protetores solares e fraldas. 0 centro de pesquisa brasileiro supre todo o mercado latino-americano na busca de novos produtos, métodos de trabalho e processos de análise e fabricação.

A seguir apresentamos a Tabela 5 com as codificações encontradas no levantamento conforme estabelecido na metodologia desta pesquisa.

A seguir apresentamos a Figura 4, com as relações encontradas no levantamento conforme estabelecido na metodologia desta pesquisa.

Não foram encontradas na Johnson \& Johnson evidências da presença de unidades de registro de desenvolvimento de mercado e diversificação, nem a categoria inovação.

A Johnson \& Johnson apresentou várias evidências de identificação de oportunidades no segmento de higiene pessoal, relacionadas ao fato de possuir muitos produtos considerados relevantes pelo mercado de baixa renda. Do mesmo modo que as outras empresas analisadas, essas oportunidades promoveram, conforme a Figura 4, a estratégia de crescimento centrada na penetração de mercado, conforme Ansoff (1958). Foram encontradas também menções a produtos diferenciados pela qualidade, assim como considerados aspiracionais, mas quanto ao desenvolvimento de produtos inteiramente novos foram encontradas poucas evidências e essas estavam relacionadas mais à adequação de produtos existentes.

\subsection{Análise}

Considerando-se a codificação de categoria identificação de oportunidades relacionada na Tabela 2, constante na metodologia, verifica-se que as empresas de bens de consumo, por serem multinacionais, abordam o mercado por regiões e não países, sendo que no caso do Brasil o mercado é visto em âmbito de América Latina. Dessa forma

Tabela 5. Codificações encontradas no caso da Johnson \& Johnson. Fonte: elaborado pelos autores.

\begin{tabular}{ccc}
\hline Categorias & \multicolumn{1}{c}{ Unidades de registro } & Resultados encontrados \\
\hline $\begin{array}{c}\text { ldentificação de } \\
\text { oportunidade }\end{array}$ & $\begin{array}{l}\text { No setor de higiene pessoal, o consumo da classe C subiu mais de 90\% entre 2001 e 2005. A Johnson \& Johnson } \\
\text { perdeu participação no mercado por não ter seguido inicialmente o mesmo caminho dos concorrentes, que } \\
\text { focaram o mercado de baixa renda. }\end{array}$ \\
\hline $\begin{array}{c}\text { Estratégia de } \\
\text { crescimento }\end{array}$ & Penetração de mercado & $\begin{array}{l}\text { Redução das margens de lucro dos produtos, aumento do volume de } \\
\text { vendas }\end{array}$ \\
\cline { 2 - 3 } lnovação & Desenvolvimento de produto & Adequação de produtos e estratégia de pirâmide de produtos \\
\hline
\end{tabular}




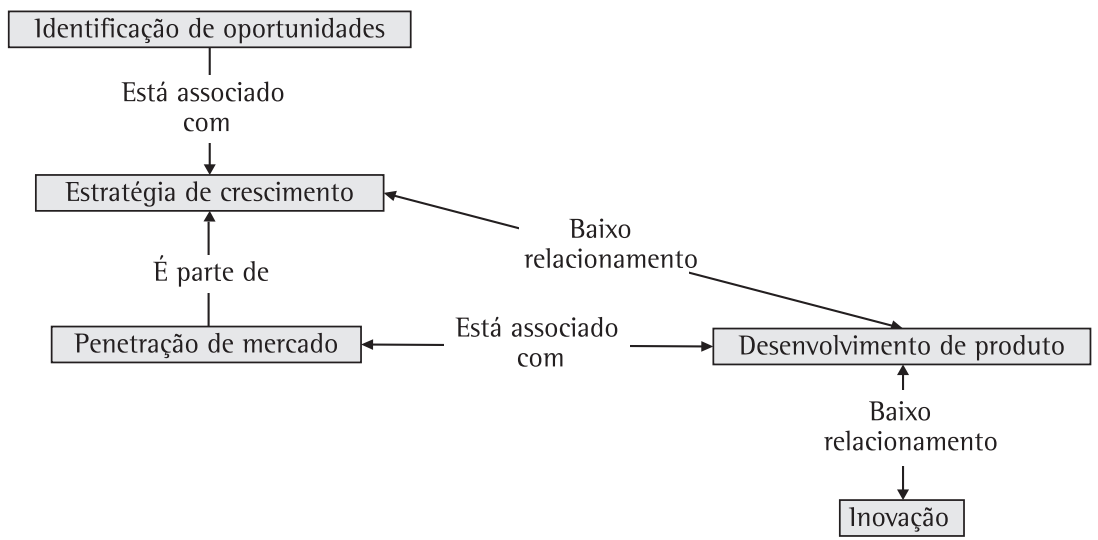

Figura 4. Evidências encontradas no caso Johnson \& Johnson. Fonte: elaborado pelos autores com base nos resultados obtios com o Atlas Tl.

Tabela 6. Síntese dos resultados encontrados. Fonte: elaborado pelos autores.

\begin{tabular}{cc}
\hline Objetivos específicos & Evidências encontradas \\
\hline $\begin{array}{c}\text { Entender como as grandes empresas estabelecidas no } \\
\text { mercado brasileiro identificam oportunidades no mercado de } \\
\text { baixa renda. }\end{array}$ & $\begin{array}{c}\text { Por meio de pesquisas de observação, as empresas buscam conhecer a cesta } \\
\text { básica de produtos considerados essenciais para a classe de baixa renda e } \\
\text { verificam se dentro do seu portfólio de produtos existem categorias relevantes } \\
\text { como oportunidade. }\end{array}$ \\
$\begin{array}{c}\text { Analisar as possíveis inovaçoses disruptivas em produtos, } \\
\text { serviços ou processos implantados pelas grandes empresas } \\
\text { estabelecidas no mercado brasileiro para atender também ao } \\
\text { mercado de baixa renda. }\end{array}$ & $\begin{array}{c}\text { Não foram encontradas evidências de inovações disruptivas conforme critérios } \\
\text { propostos por Christensen (1997). Foram encontradas com maior frequência } \\
\text { inovações sustentadoras e incrementais na adequação de produtos já } \\
\text { existentes. }\end{array}$ \\
$\begin{array}{c}\text { Entender quais estratégias de crescimento são utilizadas } \\
\text { pelas grandes empresas estabelecidas no mercado brasileiro } \\
\text { para atender também ao mercado de baixa renda. }\end{array}$ & $\begin{array}{c}\text { As empresas buscam por meio de pequenas alterações nos produtos já } \\
\text { explentes atender o mercado de baixa renda no qual já atuam e buscam } \\
\text { ampliar o patamar de consumo desse mercado, caracterizando assim, de } \\
\text { acordo com Ansoff (1958), a estratégia de penetração de mercado. }\end{array}$ \\
\hline
\end{tabular}

o foco estratégico das grandes empresas no Brasil é aumentar a escala de consumo da população de baixa renda não havendo grandes desenvolvimentos de produtos e, sim, adequações de formulação, embalagem e fracionamento para redução do preço. 0 público-alvo das multinacionais estudadas ainda exclui as classes D e E.

Nas entrevistas com os representantes das empresas estudadas observa-se preocupação inicial de pesquisar o mercado, entretanto eles apontam dificuldades iniciais nessas pesquisas, devido a diferenças de linguagem e cultura das empresas e a das classes de baixa renda, confirmando os argumentos de Anderson e Billou (2007) e SadreGhazi e Duysters (2008) em relação às dificuldades das grandes empresas frente ao mercado de baixa renda. São usadas expressões como necessidade de "pesquisa etnográfica", ou "pesquisa in loco", ou ainda "pesquisa observacional", porém de forma geral essas pesquisas envolvem a presença do pesquisador no local onde as pessoas vivem. 0 objetivo é conhecer a cesta básica de produtos essenciais consumidos por essa classe e verificar se dentro do portfólio de produtos da empresa existem categorias relevantes como oportunidade.
Quanto à categoria estratégia de crescimento, em função de a diretriz aumentar a oferta de categorias de produtos considerados relevantes para o mercado de baixa renda - as quais normalmente já são marcas conhecidas e consumidas por esse mercado - implica na estratégia de ampliação do patamar de consumo que Ansoff (1958) define como estratégia de penetração de mercado. Sendo assim, a estratégia de crescimento para o mercado brasileiro de baixa renda não apresentou a configuração do modelo de diversificação conforme Mahoney e Padian (1992) e Markides e Williamson (1996).

$\mathrm{Na}$ categoria inovação, as mesmas, quando identificadas, ocorrem a nível operacional, para conseguir levar os produtos existentes, ou variações deles, para o mercado de baixa renda. Algumas dessas ações podem ser descritas como alterações em embalagens (quantidade menor de produto para baratear preço), uso de novas formas de distribuição, simplificação da embalagem, dentre outras iniciativas de adequação ao segmento de baixa renda. Não foram encontradas evidências de inovações disruptivas conforme critérios propostos por Christensen (1997). 
Observou-se na pesquisa que a grande empresa, sempre que possível, prefere atuar no âmbito da inovação sustentadora, para não incorrer em riscos com a implantação de inovações disruptivas, confirmando o relatado por Christensen, Johnson e Rigby (2002). Foram encontradas com maior frequência inovações sustentadoras e incrementais ligadas à adequação de produtos já existentes.

A Tabela 6 apresenta uma síntese dos objetivos traçados para entender o fenômeno estudado e as evidências encontradas com base na análise de conteúdo dos casos estudados.

\section{Considerações finais}

As empresas de grande porte que atuam globalmente na produção de bens de consumo já constataram a importância do mercado de baixa renda mundial, principalmente com a abertura do mercado de países emergentes, após o advento da globalização, confirmando as expectativas de London e Hart (2004). Essas empresas estão buscando novas alternativas para atuar tanto no mercado de alto e médio poder aquisitivo como no de baixo poder aquisitivo. No caso do primeiro mercado, investe-se no desenvolvimento de produtos como alimentos funcionais, que melhoram o metabolismo e prevenem problemas de saúde, ou produtos de higiene pessoal que reduzem o envelhecimento. Já no caso do mercado de baixa renda cabe a suas subsidiárias avaliar e adequar as estratégias de sua relação com esse segmento às características do país ou região onde atuam.

Apesar de Prahalad e Hart (2002) e Prahalad e Hammond (2002) apresentarem a BOP como uma oportunidade de diversificação a ser explorada pelas empresas de grande porte, no presente estudo verificou-se que as empresas aqui estudadas não focam as classes D e E, que correspondem no mercado brasileiro ao BOP citado por esses autores.

No caso específico do mercado brasileiro, que foi objeto deste estudo, verificou-se que o foco das grandes empresas produtoras de bens de consumo estudadas foi a classe C. As empresas analisadas no presente estudo apenas identificaram se possuíam categorias de produtos relevantes para o segmento de mercado de baixa renda e agiram operacionalmente com pequenas alterações em produtos e distribuição para atendê-lo.

Segundo Neri (2010), em seu estudo a partir de dados do PNAD/1BGE, a nova classe média dominante do ponto de vista econômico concentrava 46,24\% do poder de compra em 2009. Esse fato, porém, não levou ainda as empresas estudadas a empreenderem inovações disruptivas, atendo-se a pequenas alterações em produtos para atender ao mercado de baixa renda. Estudos futuros poderiam se encarregar de investigar o porquê dessa decisão das multinacionais estudadas e, numa outra etapa, empreender estudos quantitativos para descobrir se essa é uma tendência nas empresas multinacionais que aqui operam.

$A$ adequação operacional empreendida pelas empresas estudadas visou reduzir custos de modo a tornar seus produtos acessíveis aos consumidores de baixa renda, porém, apesar desses esforços verificou-se difícil para essas empresas ganhar no preço dos concorrentes locais. Dessa forma, essas empresas conseguiram no máximo aproximar-se do valor praticado no mercado e o diferencial competitivo deu-se pelo valor da marca e pela associação dessa aos anseios aspiracionais do consumidor de baixa renda.

Nos casos observados, produtos tradicionais antes desenvolvidos quase que exclusivamente para as classes de alta renda foram adequados aos consumidores de baixa renda, numa estratégia de inovação incremental e não promovendo disrupções em seus modelos de negócio. Enquanto isso, o desenvolvimento de novos produtos, com todos os custos de pesquisa e geração de inovações, atende à nova demanda dos consumidores de maior poder aquisitivo preocupados com qualidade de vida e produtos considerados benéficos à saúde. Portanto, os resultados mostram que não foram encontradas evidências de inovações disruptivas empreendidas pelas empresas estudadas conforme critérios propostos por Christensen (1997), que incluiriam alterações nos modelos de negócio das empresas para desenvolver produtos específicos para a baixa renda, principalmente pelo fato de o foco de atenção no mercado brasileiro de baixa renda ser a chamada classe $\mathrm{C}$, que já está inserida no mercado de consumo, levando as grandes empresas estudadas a buscar a estratégia de crescimento de sua participação nesse mercado através de penetração e não de investimento em inovações disruptivas. Nesse sentido, inovações sustentadoras e incrementais foram encontradas com maior frequência relacionadas à adequação de produtos já existentes, para as três empresas investigadas neste estudo.

Como limitações do estudo, o não terem sido estudadas questões político-sociais que no momento envolviam os países emergentes, assim como outros fatores, como a má distribuição de renda, por exemplo, que por certo tem seu peso nas decisões estratégicas das empresas.

Outro fator limitante importante quanto a essa pesquisa exploratória relaciona-se ao tamanho da amostra de empresas com o perfil previsto nesta pesquisa, que impossibilita generalizações a partir dos resultados. É preciso registrar que essa limitação 
deveu-se à pouca colaboração de empresas-alvo que, talvez por desinteresse, talvez por instinto de preservação de segredo industrial ou simplesmente por uma questão de prioridade ante as enormes pressões desencadeadas pela crise financeira de 2008. Essa crítica conjuntura global desencadeou-se exatamente quando se realizava a coleta de dados primários deste trabalho era realizada, momento delicado refratário ao exame e fornecimento de dados.

Apesar da limitação imposta pelo próprio método - estudo de caso - que não permite que as conclusões obtidas sejam generalizadas para todo universo de empresas, obtiveram-se alguns insights que poderão ser utilizados em futuros estudos quantitativos como, por exemplo, investigar se a opção das empresas estudadas: empreender inovações incrementais e sustentadoras e não inovações disruptivas, fazendo pequenas alterações no produto (quantidade, embalagem) e na distribuição, ocorre num universo maior de empresas. Outro fator que poderia ser investigado em estudos futuros seria a questão do preço: associar os custos de uma inovação disruptiva ao estabelecimento de preço final do produto desenvolvido para baixa renda de forma competitiva junto aos concorrentes locais, analisando esse fenômeno à luz da cadeia produtiva.

Durante a realização deste trabalho verificou-se que as grandes empresas estudadas que atuam no mercado de consumo para as classes de maior poder aquisitivo, quando passam a atender também ao mercado de baixa renda, enfrentam dificuldades para determinar de forma mais precisa a real participação desse último segmento de mercado nos resultados finais da empresa. Portanto, uma sugestão para trabalhos futuros seria a busca de uma proposta de métricas que permitissem mensurar o desempenho obtido com o mercado de baixa renda em relação ao total dos negócios das empresas.

\section{Referências}

ANDERSON, J.; BILLOU, N. Serving the world's poor: innovation at the base of the economic pyramid. Journal of Business Strategy, v. 28, n. 2, p. 14-21, 2007. http:// dx.doi.org/10.1108/02756660710732611

ANDERSON, J.; MARKIDES, C. Strategic innovation at the base of the pyramid. MIT Sloan Managemet Review, v. 49, n. 1, p. 82-88, 2007.

ANSOFF, 1. A model for diversification. Management Science, v. 4, n. 4, p. 392-414, 1958. http://dx.doi.org/10.1287/ mnsc.4.4.392

BARDIN, L. Análise de conteúdo. 4. ed. Lisboa: Edições 70, 2008.
BOWER, J. L.; CHRISTENSEN, C. M. Disruptive Technologies: Catching the Wave. Harvard Business Review, v. 73, n. 1, p. 43-53, 1995.

BURKHAUSER, R. V.; FENG, S.; JENKINS, S. P. Using the P90/ P10 index to measure US inequality trends with current population survey data: a view from inside the Census Bureau Vaults. Working Papers Series - ECINEQ - Society for the Study of Economic Inequality, n. 72, 2007.

CARAYANNIS, E. G.; GONZALEZ, E.; WETTER, J. J. The nature and dynamics of discontinuous and disruptive innovations from a learning and knowledge management perspective. In: SHAVININA, L. V. (Org.). The international handbook on innovation. Oxford: Elsevier Science, 2003. 1200 p. http://dx.doi.org/10.1016/B978-008044198-6/50009-7

CHAN KIM, W.; MAUBORGNE, R. Blue ocean strategy. Harvard Business Review, v. 82, n. 10, p. 76-84, 2004.

CHRISTENSEN, C. M.; CRAIG, T.; HART, S. L. The great disruption. Foreign Affairs, v. 80, n. 2, p. 80-95, 2001. http://dx.doi.org/10.2307/20050066

CHRISTENSEN, C. M.; JOHNSON, M. W.; RIGBY, D. K. Foundations for growth: how to identify and build disruptive new businesses. MIT Sloan Managemet Review, v. 43, n. 3, p. 21-31, 2002.

CHRISTENSEN, C. M. The innovator's dilemma: when new technologies cause great firms to fail. Boston: Harvard Business School Press, 1997.

CHRISTENSEN, C. M. The past and future of competitive advantage. MIT Sloan Managemet Review, v. 42, n. 2, p. 105-109, 2001.

CHRISTENSEN, C. M.; RAYNOR, M. E. The innovator's solution: creating and sustaining successful growth. Boston: Harvard Business School Press, 2003.

EISENHARDT, K. M. Building theories from case study research. Academy of Management Review, v. 14, n. 4, p. 532-550, 1989.

FLICK, U. Uma introdução à pesquisa qualitativa. 2. ed. Porto Alegre: Bookman, 2004.

HART, S. L.; CHRISTENSEN, C. M. The great leap: driving innovation from the base of the pyramid. MIT Sloan Management Review, v. 44, n. 1, p. 51-56, 2002.

LONDON, T.; HART, S. L. Reinventing strategies for emerging markets: beyond the transnational model. Journal of International Business Studies, 2004.

MAHONEY, J. T.; PADIAN, J. R. The resource based view within the conversation of strategic management. Strategic Management Journal, v. 13, n. 5, p. 363-380, 1992. http://dx.doi.org/10.1002/smj.4250130505

MARKIDES, C.C.; WILLIAMSON, P. J. Corporate diversification and organizational structure: a resource-based view. Academy of Management Journal, v. 39, n. 2, p. 340-367, 1996. http://dx.doi.org/10.2307/256783

NERl, M. A Nova Classe Média: Lado Brilhante dos Pobres, setembro 2010. Disponível em: <http://www.fgv.br/cps/ $\mathrm{ncm} />$. Acesso em: 20 fev. 2011.

ORGANIZAÇÃO PARA COOPERAÇÃO E DESENVOLVIMENTO ECONÔMICO - OCDE. Manual de Oslo. 2. ed. Paris: 
Eurostat, 2004. Disponível em: <www.finep.gov.br/ imprensa/sala_imprensa/manual_de_oslo.pdf>. Acesso em: 18 jun. 2008.

PRAHALAD, C. K. A riqueza na base da pirâmide: como erradicar a pobreza com o lucro. Porto Alegre: Bookman, 2005.

PRAHALAD, C. K.; HAMMOND, A. Serving the world's poor, profitably. Harvard Business Review, v. 80, n. 9, p. 48-57, 2002.

PRAHALAD, C. K.; HART, S. L. The fortune at the bottom of the pyramid. Strategy + Business, n. 26, p. 54-67, 2002.

QUADROS, W. J. Avanços sociais no período 2004-2008. Carta Social e do Trabalho, .n. 9, 2010. Disponível em: <http://www.eco.unicamp.br/docdownload/ publicacoes/cesit/outrasPublicacoes/outrasPublicacoes/ outraPublicacao68/Carta\%20Social\%209.pdf> . Acesso em: 19 fev. 2011.
SADREGHAZI, S.; DUYSTERS, G. Serving low-income markets: rethinking multinational corporations' strategies. UNU-MERIT Working Paper Series, n. 24, 2008.

SCHUMPETER, J. A. Teoria do desenvolvimento econômico: uma investigação sobre lucros, capital, crédito, juro e ciclo econômico. São Paulo: Nova Cultural, 1982.

SEELOS, C.; MAIR, J. Profitable business models and market creation in the context of deep poverty: a strategy view. Academy of Management Perpectives, v. 21 , n. 4, p. 49-63, 2007. http://dx.doi.org/10.5465/ AMP.2007.27895339

TIDD, J.; BESSANT, J.; PAVITT, K. Managing innovation: integrating technological, market and organizational change. West Sussex: John Wiley \& Sons, 2005.

UTTERBACK, J. M. Mastering the Dynamics of Inovation. Boston: Harvard Business School Press, 1994.

YIN, R. K. Estudo de caso: planejamento e método. 2. ed. Porto Alegre: Bookman, 2001.

\begin{abstract}
The objective of this study was to identify whether major multinational companies in the Brazilian market, focused primarily on higher income classes, have promoted some kind of innovation, particularly disruptive innovations, to meet the emerging low-income market, impacting the operation management and/or supply chain of these multinationals. To this end, a multiple case study method was used at Nestlé, Unilever and Johnson \& Johnson. Results showed that multinational companies operating in the Brazilian market have not promoted disruptive innovations directed to the base of the pyramid, once they felt that the "D" and "E" classes are not attractive enough to justify investments in product development, directing investments preferentially to the " $\mathrm{C}$ " class through small changes in products and distribution. This way, no evidence of disruptive innovations was found; only sustainable and incremental innovations linked to the adequacy of existing products.
\end{abstract}

\title{
Large multinational companies innovations
} to the low-income Brazilian market

\section{Keywords}

Innovation. Disruptive innovation. Multinational company. Base of the pyramid. Growth strategy. 